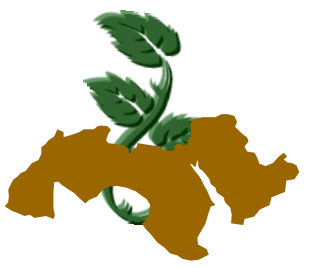

\title{
FOURIER TRANSFORM INFRARED SPECTROSCOPY TECHNIQUE FOR DETECTION OF HONEY AUTHENTICATION
}

\author{
Mehaya $^{1}$, F.M.; Mohie M. Kamil'; I.S. Ashoush ${ }^{2}$ and H.I. Khalil ${ }^{2}$ \\ 1- Food Technol. Dept., National Research Centre, Giza, Egypt \\ 2- Food Sci. Dept., Fac. Agric., Ain Shams Univ., Cairo, Egypt \\ E-mail: Dr_Fathy_nrc@yahoo.com
}

Keywords: Honey, Fourier Transform Infrared Spectroscopy (FTIR), Physico-chemical properties and authentication

\begin{abstract}
Physico-chemical properties of honey and honey samples adulterated with glucose or sucrose were determined. Total soluble solids (TSS), $\mathrm{pH}$ and electrical conductivity of honey and its adulterated samples ranged between (84.10-84.50\%), (3.80-4.63) and (11.73 - 232.32 $\mu \mathrm{S})$, respectively. Sensory properties of honey and its adulterated samples showed that, no differences in the sensorial properties were found in authentic honey and honey adulterated with $25 \%$ sucrose or $25 \%$ glucose. Increasing adulteration ratio to $50 \%$ glucose decreased taste, flavor, color and general appearance, while adulterated honey with $50 \%$ sucrose caused significant decrease in taste and general appearance. The possibility of using HPLC to detect adulteration of honey through determining their sugars content was evaluated. The obtained results indicated that, authentic honey was characterized with its higher fructose/glucose ratio (1.21) compared to adulterated honey samples (ranged between 0.35 - 0.94). FT-IR spectroscopic technique was used to evaluate honey quality. Reliability FT-IR for quantitative and qualitative analysis of sucrose, glucose and fructose were evaluated. The main FT-IR spectral bands of sucrose, glucose and fructose were identified at different concentration levels. The relationship between sugars concentration (sucrose, glucose and fructose) and its spectral bands absorbance (peak height) were evaluated to prepare sugars standard curves and their linear equations. Selected main peaks of su-
\end{abstract}

crose, glucose and fructose provide the best calibration model with correlation coefficient $\left(r^{2}\right)$ higher than (0.9). Honey samples adulterated with glucose were characterized with specific spectral peaks, in which the absorbance was increased by increasing the ratio of adulteration with glucose at $1087,1105,1189$ and $984 \mathrm{~cm}^{-1}$, while the adulteration with sucrose lead to increase in the absorbance of spectral bands of sucrose as 1054, 1149 and $984 \mathrm{~cm}^{-1}$ especially in honey adulterated with $50 \%$ sucrose.

\section{INTRODUCTION}

Honey is a natural biological product used as food and medicine since ancient times. The different proportions of nectar incorporated in honey vary depending on the geographic zone, the vegetation type as well as the flowering period of the plants (Hewitson, 2009). In general, Honey contains $12.4-20.3 \%$ moisture, less than $0.25 \%$ ash and $60.7-77.8 \%$ sugars, of which about $0-2 \%$ may be sucrose, $25.2-35.3 \%$ glucose, and $33.3-43.0 \%$ fructose (Paradkar and Irudayaraj 2001).

As a kind of health product with high nutritional value, honey is very popular for consumers. However, it has become the target of adulteration with cheaper sweeteners such as refined cane sugar, beet sugar, and corn syrup. In this concern, adulteration of honey has been reported by several investigators (Cienfuegos et al 1997; Gonzalez et al 1998; Velàzquez et al 2009). Consequently, discrimination between adulterated and authenticity of honey become very important issue for processors, retailers and consumers as well as regulatory authorities. Therefore, several techniques were investigated to detect the adulterated honey, 
for example, isotopic and chromatographic. Moreover, the stable carbon isotope ratio analysis was used as a standard method to detect adulteration of honey for several years (Arvanitoyannis et al 2005). The utility of these methods to evaluate the adulteration of honey has been revealed. Nevertheless, these techniques are time-consuming, destructive and expensive. Consequently, there is an interest in developing fast, accurate, easy to use and low-cost analytical methods to detect and quantify adulteration in honey. For this reason, spectroscopic techniques (Anjos et al 2015) and chromatographic techniques (Manzanares et al 2011) were used to evaluate some quality parameters of honey. The FT-IR technique requires low sample volume and minimal or no sample preparation is required, which greatly speeds up sample analysis (Edelmann et al 2001). Also, highperformance liquid chromatography (HPLC) has been used to identify honey authenticity using conventional sugar profile of glucose-fructose ratio (Mateo and Bosch-Reig, 1998).

This study aimed to evaluate quality attributes and adulteration of honey samples using FT-IR and HPLC techniques as a fast and simple method. The quality of honey and adulterated honey was assessed by classical methods and FT-IR spectroscopy to identify and create a unique fingerprint that resembled the samples under investigation. The obtained fingerprints could be used for quality assessments.

\section{MATERIALS AND METHODS}

\section{Materials}

Reference material of D-sucrose (GR crystals), glucose (crystals) and D-fructose (USP crystals) were obtained from Fisher Chemicals. Potassium bromide was obtained from Sigma Chemicals.

Standard solutions from sucrose, glucose and fructose were prepared in de-ionized water at concentrations from 5 to $40 \%$ in case of FT-IR technique and from 1 to $5 \mathrm{mg} / \mathrm{ml}$ for HPLC coupled with Refractive Index detector (RID).

Authentic alfa alfa honey sample was obtained from local bee keeper in Giza province, Egypt (during season 2012), and glucose syrup was obtained from local market. Also, sugar syrup was prepared in lab by dissolving $430 \mathrm{~g}$ Sugar in $225 \mathrm{ml}$ water and concentration (with lemon juice) under heating until $84.5 \%$.

Adulterated honey samples
The series of adulterated honey samples were prepared separately by mixing authentic honey with 25 or $50 \%$ glucose corn syrup and 25 or $50 \%$ cane sugar. Furthermore, sugar solution were prepared to be similar for honey using $100 \%$ glucose corn syrup, $100 \%$ cane sugar or mixing $50 \%$ glucose corn syrup with $50 \%$ cane sugar.

\section{Analytical Methods}

\section{Determination of electrical conductivity, $\mathrm{pH}$ and TSS}

The determination of electrical conductivity of a honey samples at 20\% (dry matter basis) in deionized water was measured at $20{ }^{\circ} \mathrm{C}$ using Jenway Conductivity Meter model 4510 (AOAC, 1990). Results were expressed as $\mu \mathrm{S} \mathrm{cm}-1$. The measurements of $\mathrm{pH}$ and TSS were preformed as described by Manzanares et al (2014).

\section{- Fourier Transform Infrared spectroscopy (FT-IR)}

The spectra or fingerprints of the selected samples were obtained using FT-IR spectroscopy (FT-IR-6100 Jasco, Japan) at Central Lab of National Research Center, Dokki, Giza. Samples were prepared using potassium bromide disks. FTIR spectral resolution was $4 \mathrm{~cm}^{-1}$ and wavenumber ranged from $4000-400 \mathrm{~cm}^{-1}$.

\section{- High performance liquid chromatography (HPLC)}

The HP1100 system was equipped with autosampler, quaternary pump, on-line degasser and refractive index detector, controlled with Chemstation software (Hewlett Packard, Waldbronn, Germany). The analytical column was Agilent carbohydrate column $(25 \mathrm{~cm} \times 4.6 \mathrm{~mm}$ I.D., $5 \mu \mathrm{m}$, Germany). The separation of glucose, fructose and sucrose was performed as isocratic separation with acetonitrile: water $(75: 25 \%)$ as mobile phase. The separated sugars were detected using refractive index detector and the quantitation was integrated by Chemstation chromatographic software interfaced to a personal computer.

Sensory Evaluation 
Sensory properties of authentic and adulterated honey samples were evaluated according to Paulus et al (1979). The samples were served to ten trained panelist to evaluate sensory attributes (color, taste, odor, texture and general acceptability) using 9 points descriptive scale. According to the scoring tables, scores (7-9) indicated "high quality", scores (4-6) indicated "moderate quality and scores (1-3) indicated the limit of "unacceptability".

\section{Statistical analysis}

Results were evaluated statistically using analysis of variance as reported by McClave and Benson (1991).

\section{RESULTS AND DISCUSSION}

\section{- Physicochemical Properties}

Total Soluble Solids (TSS) is the most important measurement related to honey quality, where increasing TSS is related to lower moisture content and could be related to lowering the risk of spoilage due to fermentation. Table (1) shows that total soluble solids (TSS) of authentic honey (control) was $84.47 \%$ while, honey samples adulterated with sugar cane or glucose syrup between 84.50 $84.10 \%$. This result indicated that, TSS was not affected during processing steps of adulteration with sucrose or glucose. Therefore, TSS is not a reliable indicator for detecting adulteration.

Honey is acidic due to the presence of organic acids that contribute to honey flavor and stability against microbial spoilage. Table (1) shows that $\mathrm{pH}$ values of authentic honey (control) was 4.49, while $\mathrm{pH}$ values of honey samples adulterated with 25, 50 and $100 \%$ glucose were 4.63, 4.01 and 4.53 , respectively. Also, $\mathrm{pH}$ values of honey adulterated with 25,50 and $100 \%$ sucrose decreased to $3.95,3.80$ and 3.72 , respectively. Moreover, mixed syrup of $50 \%$ glucose and $50 \%$ sucrose was 3.84. These results indicated that there were slight differences in acidity of adulterated honey, where slight higher acidity of adulterated honey of sucrose syrup could be due to using lemon juice to avoid sugar crystallization.

Regarding the electrical conductivity a comparative study was carried out between the authentic honey and those adulterated with different glucose and sucrose percentages as shown in Table (1). Results indicated that, there were significant differences $(p<.05)$ in electrical conductivity between authentic honey $(232.32 \mu \mathrm{S})$ and adulterated honey samples, where electrical conductivity values decreased in honey adulterated with 25, 50 and $100 \%$ sucrose (ranged between $59.51-180.84 \mu \mathrm{S}$ ); and decreased in honey adulterated with 25, 50 and $100 \%$ glucose (ranged between 11.73-174.13 $\mu \mathrm{S})$. As stated by (Codex Alimentarius Commetee, 2001 and European Commission, 2002) electrical conductivity should not be more than 800 $\mu \mathrm{S}$ in alfa alfa honey and this reflect the amount of ash content (Sancho et al 1991). Therefore, the obtained result could be used to predict the quality (ash \& minerals) of honey, while the confirmation test still needed to detect honey adulteration.

Furthermore, the possibility of using sensory evaluation to detect the authenticity of honey samples was studied. Table (2) shows that the best sensorial properties were found in authentic honey (control sample) and honey adulterated with $25 \%$ sucrose, where there was no significant difference between them. Also, adulterating honey with $25 \%$ glucose syrup did not cause significant change in taste, flavor and consistency, while color and general appearance were significantly affected. Increasing adulteration ratio to $50 \%$ glucose decreased taste, flavor, color and general appearance compared to authentic honey, while consistency was not affected. Using $50 \%$ sucrose to prepare adulterated honey caused significant decrease in taste and general appearance, while flavor, color and consistency were not significantly affected. Furthermore, using $100 \%$ glucose syrup or $100 \%$ sucrose caused drastic changes in all sensory parameters except consistency compared to authentic honey. It could be concluded that, determination of sensory properties of honey was not enough to detect adulterated honey, but it needs also to be tested to confirm the authenticity of honey.

\section{High performance liquid chromatography}

Sugars are the main constituents of honey, accounting for about $95 \%$ of honey dry matter. Especially fructose and glucose concentration as well as the fructose/glucose ratio are useful for the classification of unifloral honeys (Oddo et al 1995; Oddo and Piro, 2004). Therefore, high performance liquid chromatography (HPLC-RID) was used to evaluate authenticity of honey and adulterated honey samples. The obtained standard curves of fructose, glucose and sucrose are clearly shown in Fig. (1). 
Arab Univ.

J. Agric. Sci., Ain Shams Univ., Cairo, 23(2), 549-562, 2015

Table 1. Effect of adulteration of honey with glucose syrup or cane sugar on Total Soluble Solids (TSS), $\mathrm{pH}$ and electrical conductivity (mean $\pm \mathrm{SD}$ )

\begin{tabular}{|c|c|c|c|}
\hline Samples & TSS & $\mathrm{pH}$ value & $\begin{array}{l}\text { Electrical Conductivity } \\
\qquad(\mu S)\end{array}$ \\
\hline Authentic honey & $84.47 \pm 0.896$ & $4.49^{a} \pm 0.006$ & $232.32^{\mathrm{a}} \pm 3.5$ \\
\hline \multicolumn{4}{|c|}{ Adulterated honey with : } \\
\hline Glucose (25\%) & $84.35 \pm 0.76$ & $4.63^{a} \pm 0.045$ & $174.13^{c} \pm 2.33$ \\
\hline Glucose $(50 \%)$ & $84.13 \pm 1.24$ & $4.01^{b} \pm 0.059$ & $120.67^{e} \pm 2.65$ \\
\hline Sucrose $(25 \%)$ & $84.20 \pm 0.956$ & $3.95^{d} \pm 0.065$ & $180.84^{b} \pm 3.11$ \\
\hline Sucrose $(50 \%)$ & $84.43 \pm 0.117$ & $3.80^{c} \pm 0.046$ & $141.46^{d} \pm 1.43$ \\
\hline Sucrose syrup (100\%) & $84.50 \pm 0.362$ & $3.72^{c} \pm 0.035$ & $59.51^{f} \pm 0.65$ \\
\hline Glucose syrup (100\%) & $84.37 \pm 0.503$ & $4.53^{a} \pm 0.121$ & $11.73^{h} \pm 0.11$ \\
\hline Glucose: Sucrose (1:1) & $84.10 \pm 1.01$ & $3.84^{c} \pm 0.021$ & $34.595^{9} \pm 0.87$ \\
\hline
\end{tabular}

$a, b, c, d, f, g, h$ : Means having different letter exponents within column are significantly different $(p<0.05)$

Table 2. Sensory evaluation of adulterated honey. (mean \pm SD of 10 panelists)

\begin{tabular}{|c|c|c|c|c|c|}
\hline Samples & Taste & Flavor & Color & texture & $\begin{array}{c}\text { General } \\
\text { Appearance }\end{array}$ \\
\hline Authentic honey & $\begin{array}{r}17.5^{\mathrm{a}} \\
\pm 1.35 \\
\end{array}$ & $\begin{array}{r}17.1^{\mathrm{a}} \\
\pm 1.73 \\
\end{array}$ & $\begin{array}{c}17.7^{\mathrm{a}} \\
\pm 1.49 \\
\end{array}$ & $\begin{array}{r}16.7^{a b} \\
\pm 2.26 \\
\end{array}$ & $\begin{array}{c}18.1^{\mathrm{a}} \pm \\
0.74\end{array}$ \\
\hline \multicolumn{6}{|c|}{ Adulterated honey with : } \\
\hline $25 \%$ Glucose & $\begin{array}{l}16.3 \mathrm{ab} \\
\pm 1.57\end{array}$ & $\begin{array}{l}15.3^{\mathrm{ab}} \\
\pm 2.00\end{array}$ & $\begin{array}{l}15.8^{b c} \\
\pm 2.20\end{array}$ & $\begin{array}{l}16.8^{\mathrm{ab}} \\
\pm 2.30\end{array}$ & $\begin{array}{r}16.0^{\mathrm{b}} \\
\pm 2.54\end{array}$ \\
\hline $50 \%$ Glucose & $\begin{array}{l}15.2^{\mathrm{bc}} \\
\pm 1.48\end{array}$ & $\begin{array}{r}14.9^{b} \\
\pm 2.18\end{array}$ & $\begin{array}{l}14.8^{\mathrm{cd}} \\
\pm 1.54\end{array}$ & $\begin{array}{l}16.2^{\mathrm{ab}} \\
\pm 2.44\end{array}$ & $\begin{array}{l}15.5^{\mathrm{bc}} \\
\pm 1.65\end{array}$ \\
\hline $25 \%$ Sucrose & $\begin{array}{c}17.3^{\mathrm{a}} \\
\pm 1.83\end{array}$ & $\begin{array}{c}17.1^{\mathrm{a}} \\
\pm 2.02\end{array}$ & $\begin{array}{l}16.9^{\mathrm{ab}} \\
\pm 1.91\end{array}$ & $\begin{array}{r}17.9^{a} \\
\pm 1.85\end{array}$ & $\begin{array}{r}16.9^{a b} \\
\pm 1.80\end{array}$ \\
\hline $50 \%$ Sucrose & $\begin{array}{l}15.4^{\mathrm{dc}} \\
\pm 2.46\end{array}$ & $\begin{array}{l}15.3^{\mathrm{ab}} \\
\pm 2.71\end{array}$ & $\begin{array}{l}16 .{ }^{a b c} 1 \\
\pm 1.85\end{array}$ & $\begin{array}{l}16.9^{\mathrm{ab}} \\
\pm 2.23\end{array}$ & $\begin{array}{l}15.6^{\mathrm{bc}} \\
\pm 3.31\end{array}$ \\
\hline $100 \%$ Sucrose & $\begin{array}{l}14.6^{\mathrm{bc}} \\
\pm 1.90\end{array}$ & $\begin{array}{l}14.4^{b} \\
\pm 2.32\end{array}$ & $\begin{array}{l}15.7^{b c} \\
\pm 2.00\end{array}$ & $\begin{array}{r}15.4^{\mathrm{b}} \\
\pm 2.41\end{array}$ & $\begin{array}{l}15.5^{\mathrm{bc}} \\
\pm 2.27\end{array}$ \\
\hline $100 \%$ Glucose & $\begin{array}{l}14.1^{c} \\
\pm 2.77\end{array}$ & $\begin{array}{c}15.1^{\mathrm{b}} \\
\pm 2.13\end{array}$ & $\begin{array}{l}14.5^{\mathrm{cd}} \\
\pm 1.78\end{array}$ & $\begin{array}{r}15.5^{b} \\
\pm 3.06\end{array}$ & $\begin{array}{r}13.8^{c} \\
\pm 2.74\end{array}$ \\
\hline $50 \%$ Glucose $+50 \%$ & $14.8^{\mathrm{bc}}$ & $14.4^{\mathrm{b}}$ & $13.8^{d}$ & $16.2^{\mathrm{ab}}$ & $14.9^{\mathrm{bc}}$ \\
\hline Sucrose & \pm 2.15 & \pm 1.51 & \pm 1.55 & \pm 2.10 & \pm 1.37 \\
\hline
\end{tabular}


a, b, c, d: Means having different letter exponents within column are significantly different $(p<0.05)$
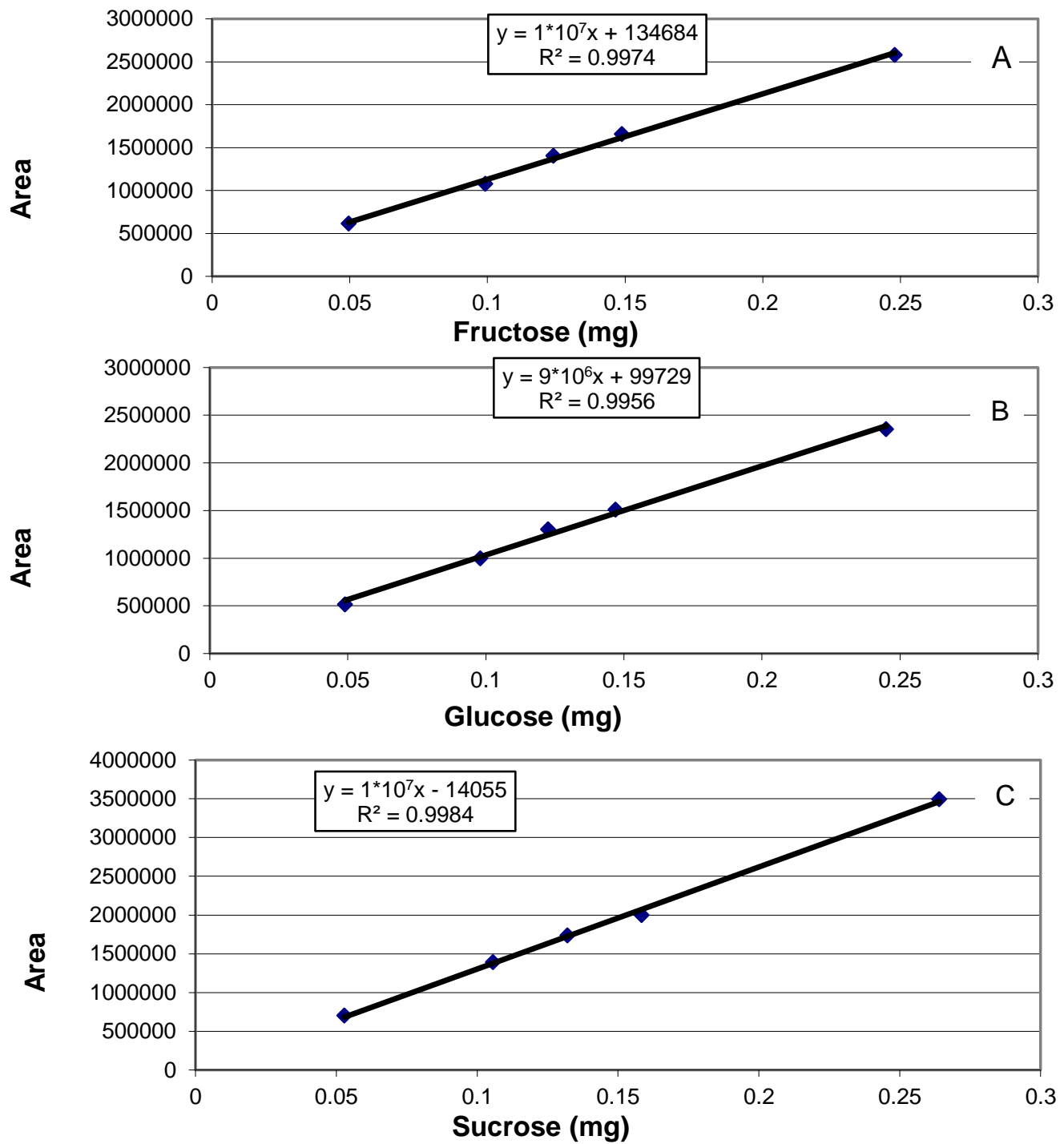

Fig. 1. HPLC standard curves of fructose (A), glucose (B) and sucrose (C).

The possibility of using HPLC to detect adulteration of honey through determining their sugars content was evaluated as shown in Table (3). The obtained results indicated that, authentic honey is characterized by its higher glucose/fructose ratio (1.21) compared to adulterated honey samples (ranged between $0.35-0.94$ ). This result agree with Cotte et al (2003). Also, adulterated honey with sucrose showed higher fructose/glucose ratio than adulterated honey with glucose syrup. This result could be due to acid hydrolysis of sucrose syrup during preparing adulterated honey. Using
HPLC to determine sugars profile could be recommended as a confirmed method for the easy and fast method such as (FT-IR).

\section{FT-IR Spectroscopy}

In the recent years, (FT-IR) spectroscopy (4000-400 $\left.\mathrm{cm}^{-1}\right)$ has gained wide acceptance in the field of food science for quantitative and qualitative analysis because of its advantages over other analytical techniques. This technique is rapid, low-cost, non-destructive and easy to use. Therefore, FT-IR spectral bands of sucrose, glucose and 
fructose were evaluated to select the main peaks that could be used for identification and quantification of sugars in honey.

Table 3. Sugars contents of adulterated honey as determined by high performance liquid chromatography (HPLC)

\begin{tabular}{|c|c|c|c|c|c|}
\hline & Fructose (\%) & Glucose (\%) & F/G ratio & Sucrose (\%) & Total (\%) \\
\hline Authantic Honey & 34.675 & 28.737 & 1.21 & 2.855 & 66.267 \\
\hline \multicolumn{7}{|c|}{ Adulterated honey with } & \\
\hline $25 \%$ Glucose & 24.367 & 26.961 & 0.901 & 2.604 & 53.932 \\
$50 \%$ Glucose & 21.905 & 26.589 & 0.821 & 2.804 & 51.298 \\
$25 \%$ Sucrose & 28.935 & 30.759 & 0.941 & 12.799 & 72.493 \\
$50 \%$ Sucrose & 26.245 & 28.86 & 0.91 & 19.404 & 74.509 \\
\hline \multicolumn{7}{|c|}{ Formulated sugar syrup } & & \\
\hline Glucose (100\%) & ND & 16.783 & -- & -- & 16.783 \\
Sucrose (100\%) & 5.196 & 7.168 & 0.72 & 50.738 & 63.102 \\
Glucose + Sucrose (1:1) & 3.998 & 11.22 & 0.35 & 28.163 & 43.381 \\
\hline
\end{tabular}

\section{- Sugars calibration Curve}

Fig. (2) shows spectral bands of different sucrose concentrations, ranging from $5 \%$ to $40 \%$. The intensity of the absorption peaks of the corresponding sucrose shows a concentrationdependent change in the spectra. The main FT-IR spectra of sucrose solution at different concentration levels are clearly shown in Fig. (2) and given in Table (4). Sucrose solution shows multiple peaks that are significantly different in the range of 900 to $1300 \mathrm{~cm}^{-1}$ wavenumber. The predominate peaks in the 900 to $1300 \mathrm{~cm}^{-1}$ wavenumber range of the spectrum are given in Table (4) as well as their peak assignments. The main peaks are concentrated at $1048 \pm 5 \mathrm{~cm}^{-1}$ (C-O stretching), $1138 \pm$ $5 \mathrm{~cm}^{-1}$ (C-O-C antisymmetric stretching) and $990 \pm$ $5 \mathrm{~cm}^{-1}\left(\mathrm{CH}_{2}\right.$ out-of-plane deformation).

Peaks height of dominant spectral absorption band at 1138, 1048 and $990 \mathrm{~cm}^{-1} \pm 5 \mathrm{~cm}^{-1}$ were calculated for each concentration (triplicate) using the corrected baseline method. The relationship between sucrose concentration and the absorbance (peak height) with its mathematical relationships are presented in Fig. (3). This figure exhibits linear relationship; and represents the direct univariate standard curve of the sucrose (the coeffi- cient of determination $\mathrm{R}^{2}$ ranged between 0.96 0.98).

The main FT-IR spectra of glucose at different concentration levels are presented in Fig. (4). The predominate peaks in the 985 to $1152 \mathrm{~cm}^{-1}$ wavenumber range of the spectrum and their relation to glucose concentration are given in Table (5) as well as their peak assignments. The main peaks are concentrated at $1152 \pm 5 \mathrm{~cm}^{-1}$ (C-O-C antisymmetric stretch), $1105 \pm 5 \mathrm{~cm}^{-1}$ (C-O and $\mathrm{C}-\mathrm{C}$ vibrations), $1077 \pm 5 \mathrm{~cm}^{-1}$ (Stretching CO \& CC), $1030 \pm 5 \mathrm{~cm}^{-1}$ (Stretching CO) and $985 \pm 5 \mathrm{~cm}^{-1}$ ( $\mathrm{CH}_{2}$ out-of-plane deformation).

The relationship between glucose concentration and the absorbance (peak height) are presented in Fig. (5). Glucose standard curves were characterized with their linear relationship; and their higher coefficient of determination, where $\mathrm{R}^{2}$ were higher than 0.9 at different selected wave numbers.

Furthermore, FT-IR spectra (fingerprints) of different fructose concentration were determined as shown in Fig. (6). The main FT-IR spectra of fructose were found in the region of 1057 to $1632 \mathrm{~cm}^{-1}$. The main peaks are concentrated at $1632 \pm 5 \mathrm{~cm}^{-1}$ (bending $\mathrm{OH}$ ), $1084 \pm 5 \mathrm{~cm}^{-1}$ (Stretching CO \& CC) and $1057 \pm 5 \mathrm{~cm}^{-1}$ (C-O stretch). Peak heights of dominant spectral absorption band at different fruc- 
tose concentrations are clearly shown in Table (6). The relationship between concentration of fructose and the absorbance (peak height) of main peaks are presented in Fig. (7). The obtained standard curves are characterized with their linear relation- ship and higher $R^{2}(>0.9)$ for all selected spectral bands.

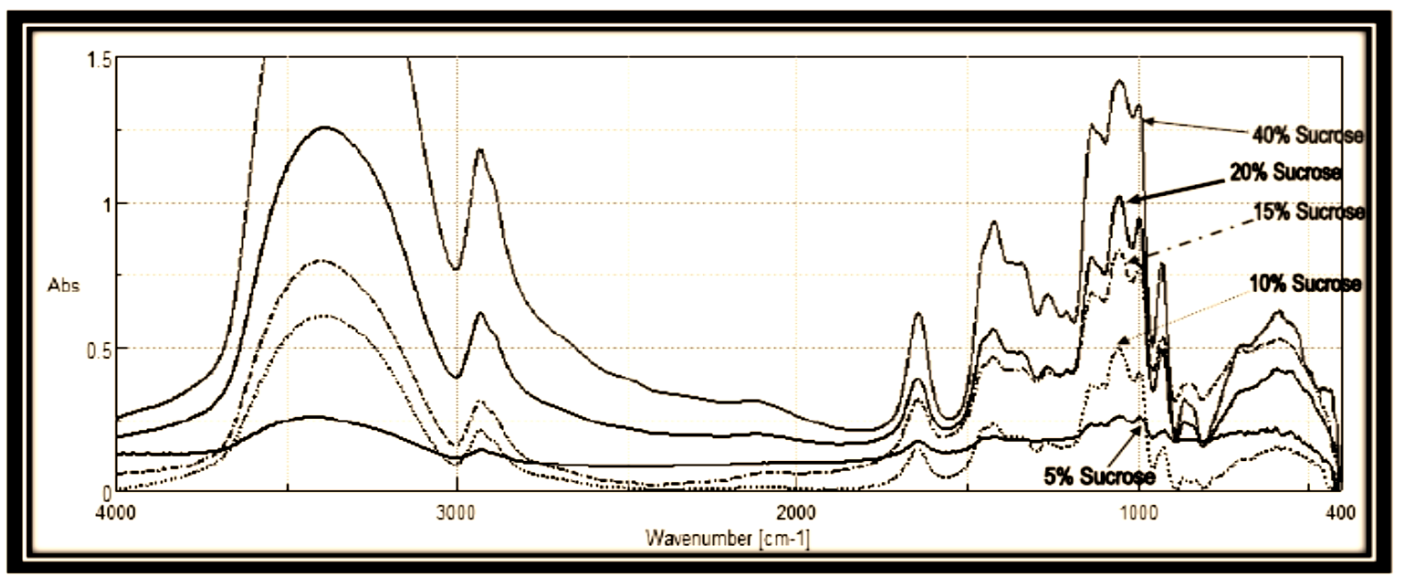

Fig. 2. FT-IR spectra of sucrose solution (dried on $\mathrm{KBr}$ disc) at 5, 10, 15, 20 and $40 \%$ concentration levels

Table 4. FT-IR spectral bands of sucrose solution (dried on $\mathrm{KBr}$ disc) at wave numbers 1048 (A), 1138 (B) and $990(\mathrm{C}) \pm 5 \mathrm{~cm}^{-1}$

\begin{tabular}{|c|c|c|c|c|c|c|c|c|}
\hline \multirow{2}{*}{$\begin{array}{c}\text { Wave } \\
\text { No. } \mathbf{~ c m}^{-1}\end{array}$} & \multicolumn{7}{|c|}{ Intensity } & \multirow{2}{*}{ Assignments } \\
\cline { 2 - 8 } & $\mathbf{0 . 5}$ & $\mathbf{2 . 5}$ & $\mathbf{7 . 5}$ & $\mathbf{1 0}$ & $\mathbf{1 5}$ & $\mathbf{2 0}$ & $\mathbf{4 0}$ & \\
\hline $1048 \pm 5$ & 0.366 & 0.431 & 0.564 & 0.695 & 0.751 & 1.096 & 1.455 & C-O stretching \\
$1138 \pm 5$ & 0.318 & 0.377 & 0.508 & 0.542 & 0.600 & 0.907 & 1.415 & C-O-C antisymmetric stretch \\
$990 \pm 5$ & 0.379 & 0.453 & 0.588 & 0.699 & 0.826 & 1.228 & 1.738 & CH2 out-of-plane deformation \\
\hline
\end{tabular}

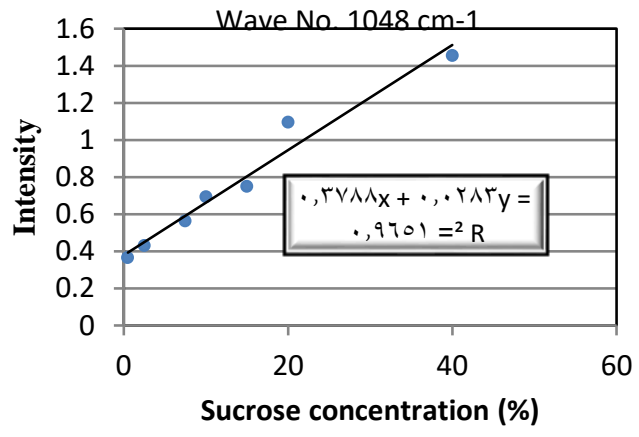

(A)

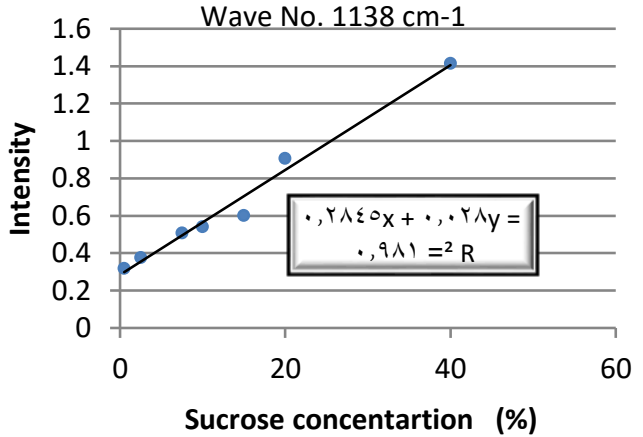

(B) 


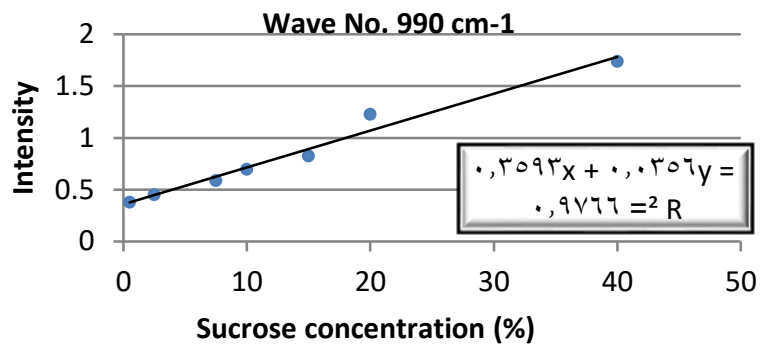

(C)

Fig. 3. FT-IR of sucrose solution (dried on $\mathrm{KBr}$ disc) standard curves at wave numbers $1048(\mathrm{~A}), 1138(\mathrm{~B})$ and 990 (C) $\pm 5 \mathrm{~cm}^{-1}$.

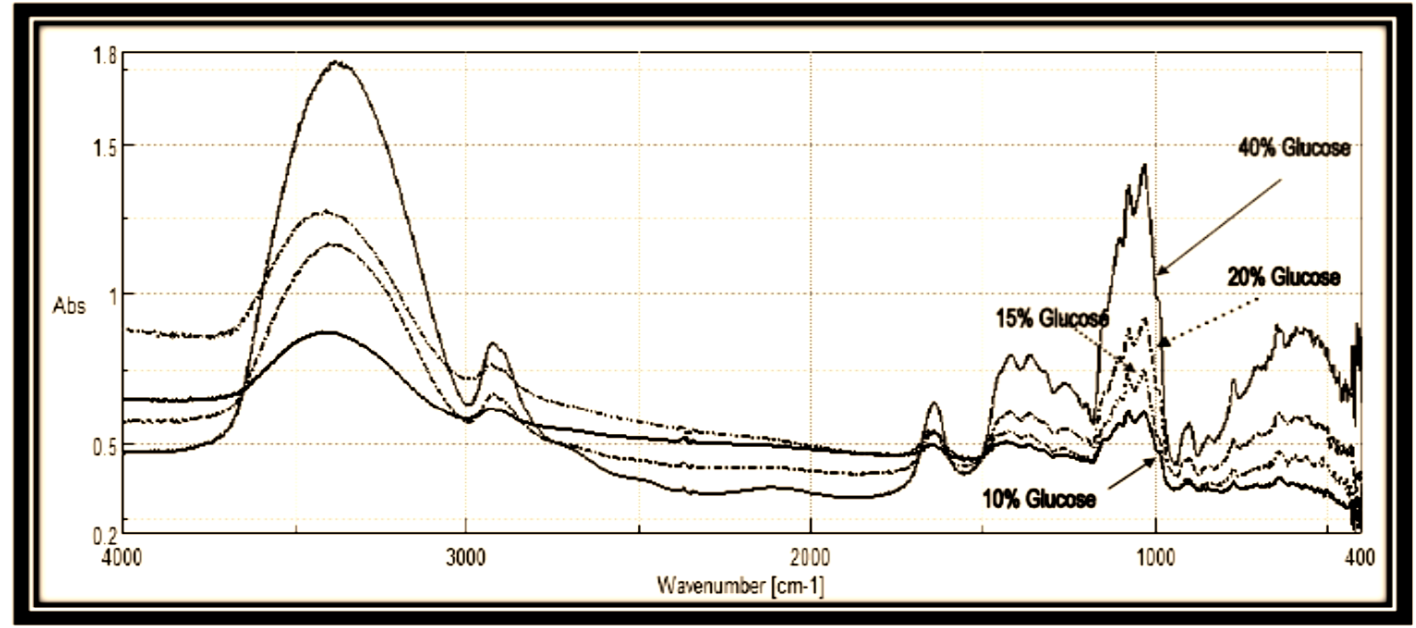

Fig. 4. FT-IR spectra of glucose solution (dried on $\mathrm{KBr}$ disc) at concentration levels 10, 15, 20 and 40\%

Table 5. FT-IR spectral bands of glucose solution (dried on $\mathrm{KBr}$ disc) at 1152 (A), 1105 (B) 1077 (C), 1030 (D) and $985(E) \pm 5 \mathrm{~cm}^{-1}$

\begin{tabular}{|c|c|c|c|c|c|c|c|}
\hline \multirow{3}{*}{$\begin{array}{c}\text { Wave No. } \\
\qquad \mathrm{cm}^{-1}\end{array}$} & \multicolumn{6}{|c|}{ Intensity } & \multirow{3}{*}{ Assignments } \\
\hline & \multicolumn{6}{|c|}{ Concentration (\%) } & \\
\hline & 1 & 7.5 & 10 & 15 & 20 & 40 & \\
\hline $1152 \pm 5$ & 0.203 & 0.236 & 0.256 & 0.308 & 0.410 & 1.134 & $\mathrm{C}-\mathrm{O}-\mathrm{C}$ antisymmetric stretch \\
\hline $1105 \pm 5$ & 0.208 & 0.296 & 0.346 & 0.432 & 0.557 & 1.415 & $\mathrm{C}-\mathrm{O}$ and $\mathrm{C}-\mathrm{C}$ vibrations \\
\hline $1077 \pm 5$ & 0.221 & 0.409 & 0.501 & 0.637 & 0.768 & 1.839 & Stretching $\mathrm{CO}$ and $\mathrm{CC}$ \\
\hline $1030 \pm 5$ & 0.215 & 0.341 & 0.408 & 0.523 & 0.678 & 1.641 & Stretching CO \\
\hline $985 \pm 5$ & 0.156 & 0.232 & 0.257 & 0.337 & 0.523 & 1.385 & $\mathrm{CH}_{2}$ out-of-plane deformation \\
\hline
\end{tabular}




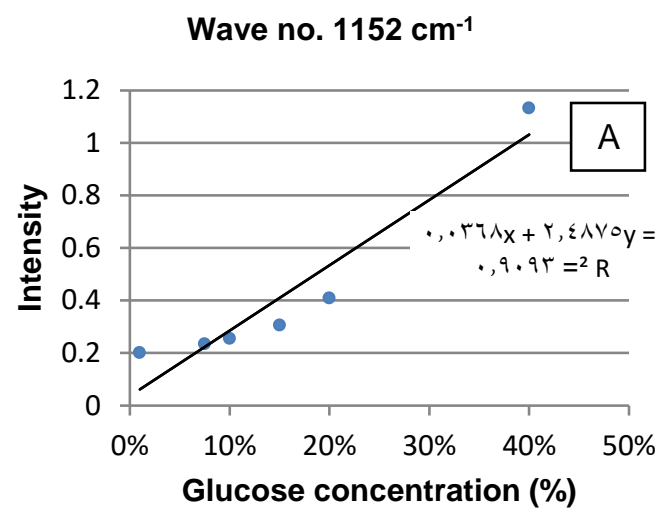

(A)

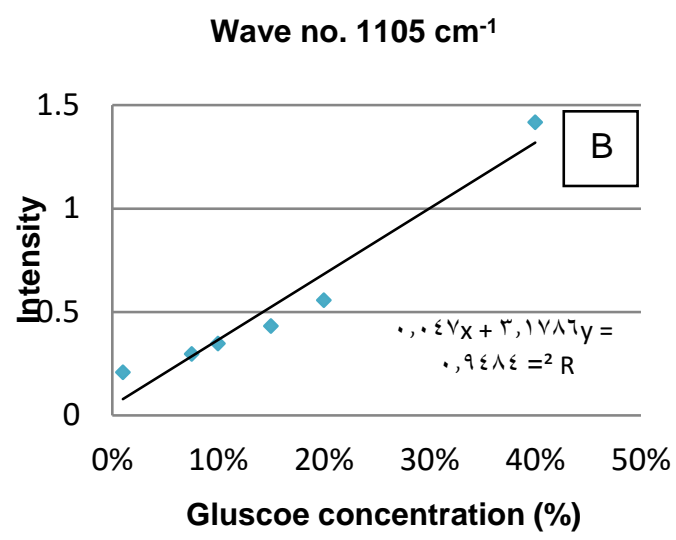

(B)

Wave no. $1030 \mathrm{~cm}^{-1}$

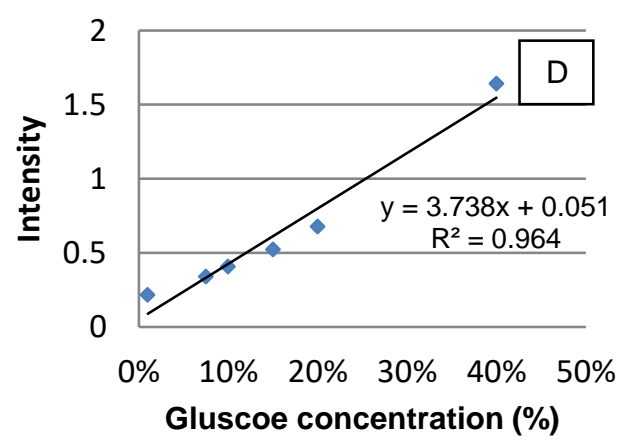

Wave No. $985 \mathrm{~cm}^{-1}$

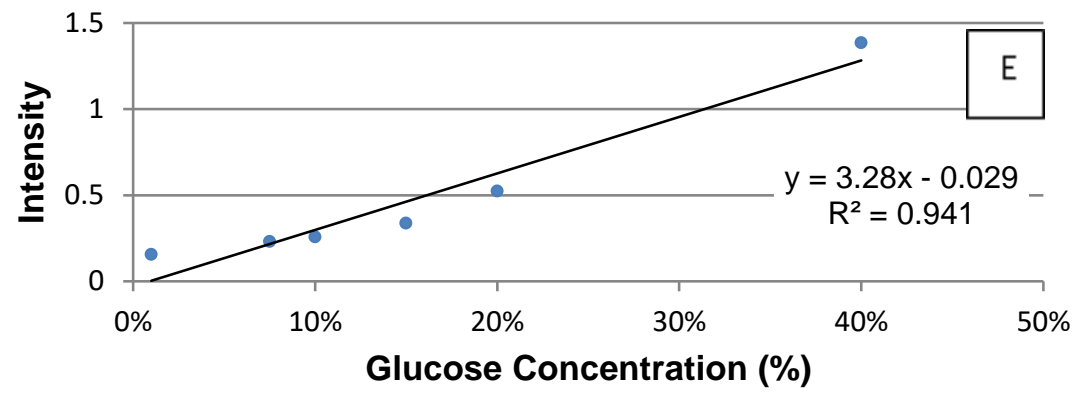

Fig. 5. Standard curves of glucose at several wave numbers (A-E) 


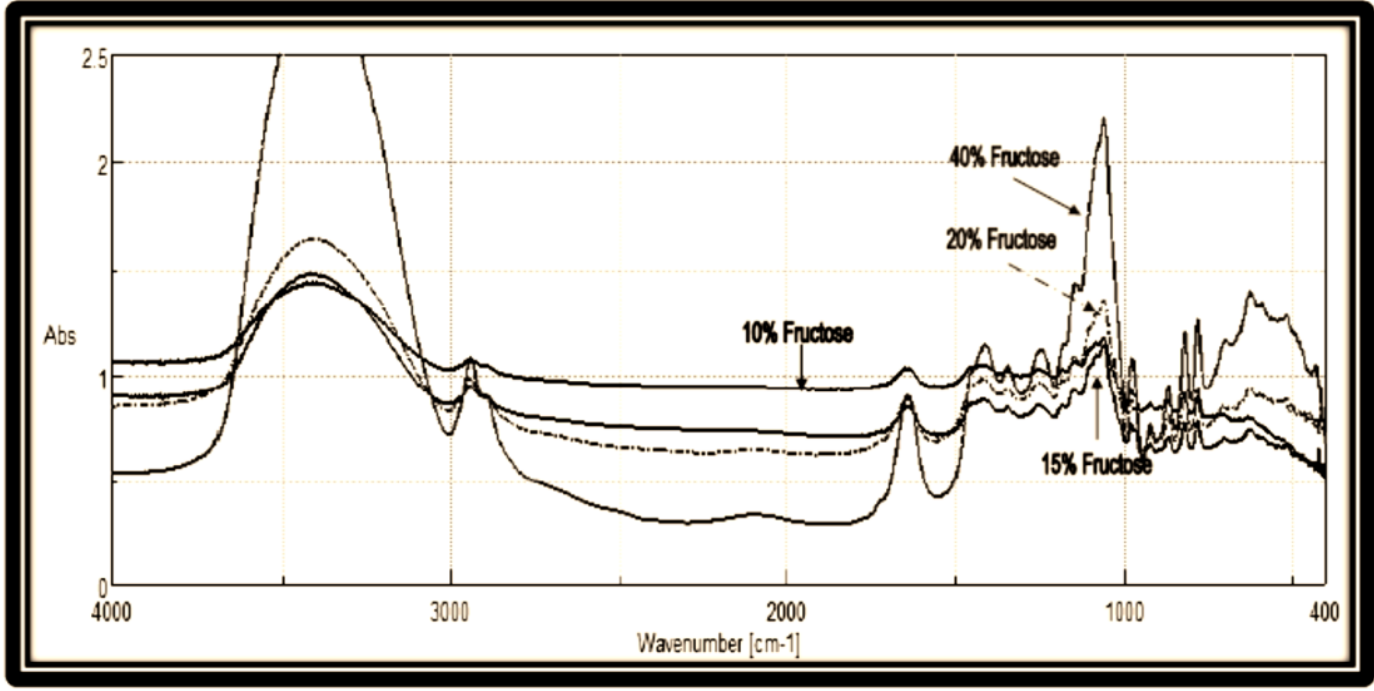

Fig. 6. FT-IR spectra of fructose solution (dried on $\mathrm{KBr}$ disc) at 10, 15, 20 and $40 \%$ concentration level

Table 6. FT-IR spectral bands of fructose solution (dried on $\mathrm{KBr}$ disc) standard curve at 1632 (A), 1084 (B) and 1057 (C) $\pm 5 \mathrm{~cm}^{-1}$

\begin{tabular}{|c|c|c|c|c|c|c|c|c|c|}
\hline \multirow{2}{*}{$\begin{array}{c}\text { Wave } \\
\text { No. } \mathbf{~ c m}^{-1}\end{array}$} & \multicolumn{7}{|c|}{ Intensity } & \multirow{2}{*}{ Assignments } \\
\cline { 2 - 9 } & $\mathbf{1}$ & $\mathbf{2 . 5}$ & $\mathbf{5}$ & $\mathbf{7 . 5}$ & $\mathbf{1 0}$ & $\mathbf{1 5}$ & $\mathbf{2 0}$ & $\mathbf{4 0}$ & \\
\hline $1632 \pm 5$ & 0.220 & 0.244 & 0.284 & 0.386 & 0.361 & 0.375 & 0.507 & 0.995 & bending OH \\
$1084 \pm 5$ & 0.265 & 0.470 & 0.511 & 0.551 & 0.580 & 0.768 & 0.871 & 2.752 & Stretching CO \& CC \\
$1057 \pm 5$ & 0.310 & 0.510 & 0.602 & 0.715 & 0.720 & 1.058 & 0.994 & 3.713 & C-O stretch \\
\hline
\end{tabular}
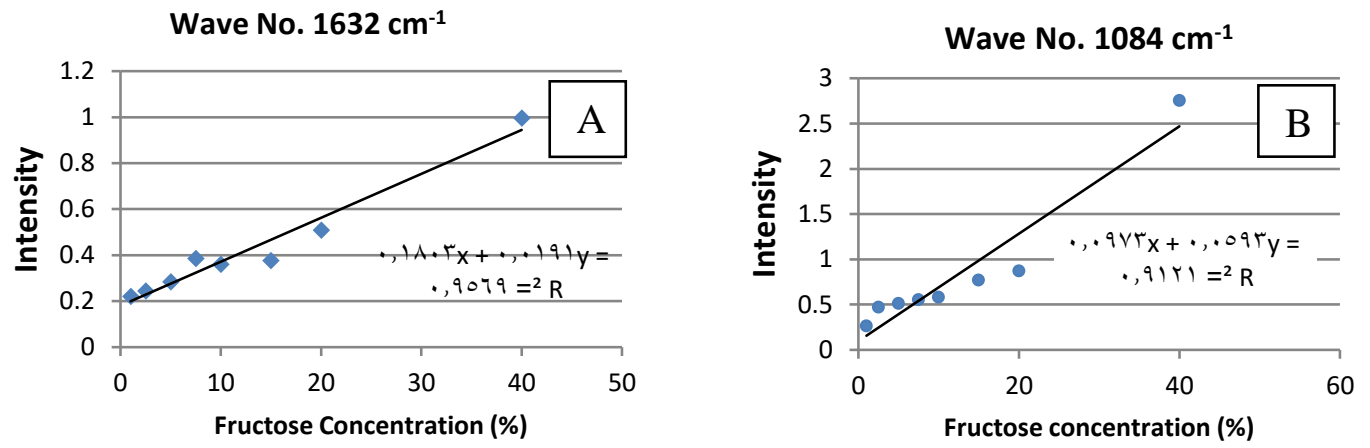


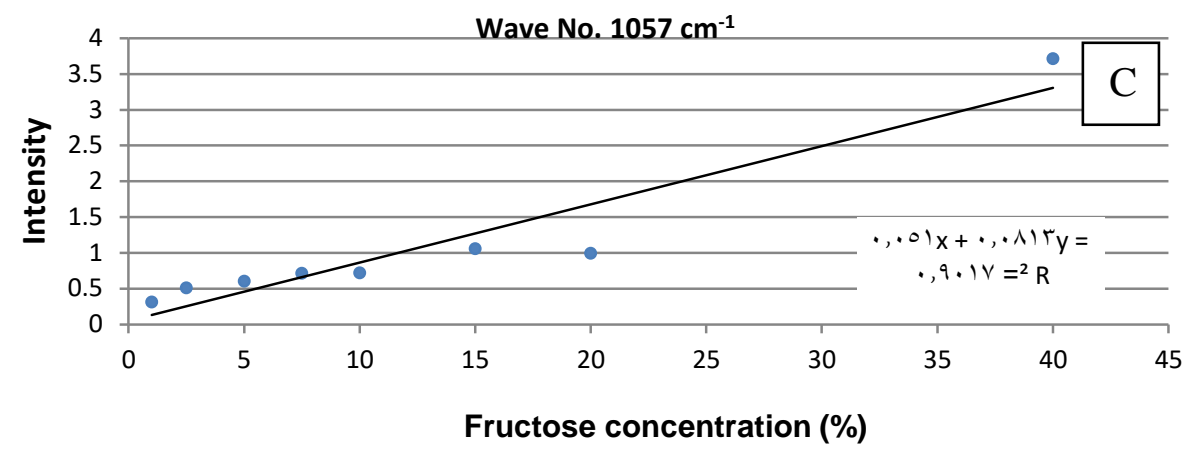

(C)

Fig. 7. Standard curves of fructose solution (dried on $\mathrm{KBr}$ disc) at 1632 (A), 1084 (B) and 1057 (C) $\pm 5 \mathrm{~cm}^{-1}$.

FT-IR spectral of authentic and adulterated honey

FT-IR spectral bands of authentic and adulterated honey with different ratios of glucose and sucrose are shown in Figs ( 8 \& 9). The appearance shape for spectra of all samples are similar by naked eye, but each of them was differ from others in absorbance degree. The Spectra of the samples show absorbance bands at three regions (3363 \pm 6 : 2886 $\left.\pm 3 \mathrm{~cm}^{-1}\right),\left(1640 \pm 3: 1260 \pm 1 \mathrm{~cm}^{-1}\right)$ and $\left(1186 \pm 10: 921 \pm 2 \mathrm{~cm}^{-1}\right)$. These bands are representative of the chemical groups of components present in the pure and adulterated honey sam- ples. Assignments of the functional groups of the components corresponding to the vibration modes was based on identification of the spectra peaks and matching the frequency with the corresponding chemical group that absorbs in this region.

The region $\left(800: 1500 \mathrm{~cm}^{-1}\right)$ corresponds to the absorption zones of the 3 major sugar constituents of honey, fructose, glucose and sucrose, while the $750: 900 \mathrm{~cm}^{-1}$ region is the anomeric region and is characteristic of the saccharide configuration (Ozaki, 1999).

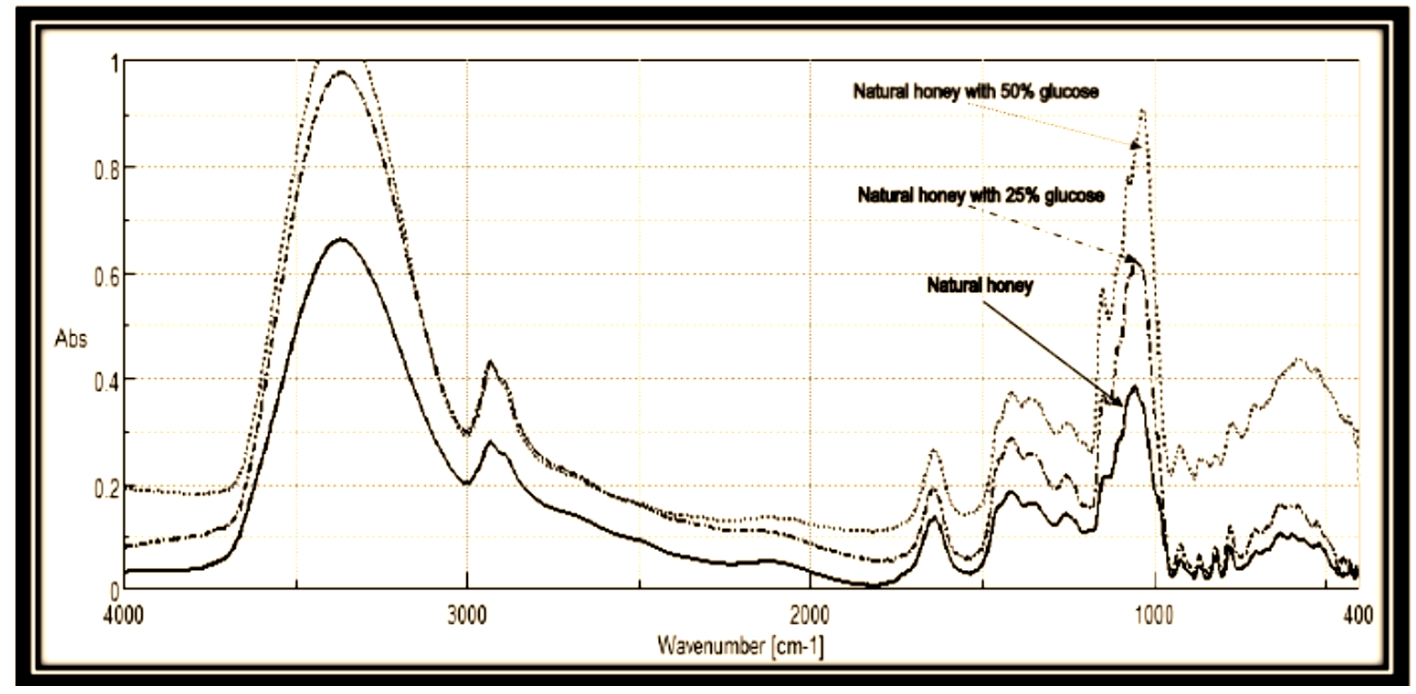

Fig. 8. FT-IR spectral bands of authentic and adulterated honey with different concentration levels of glucose 


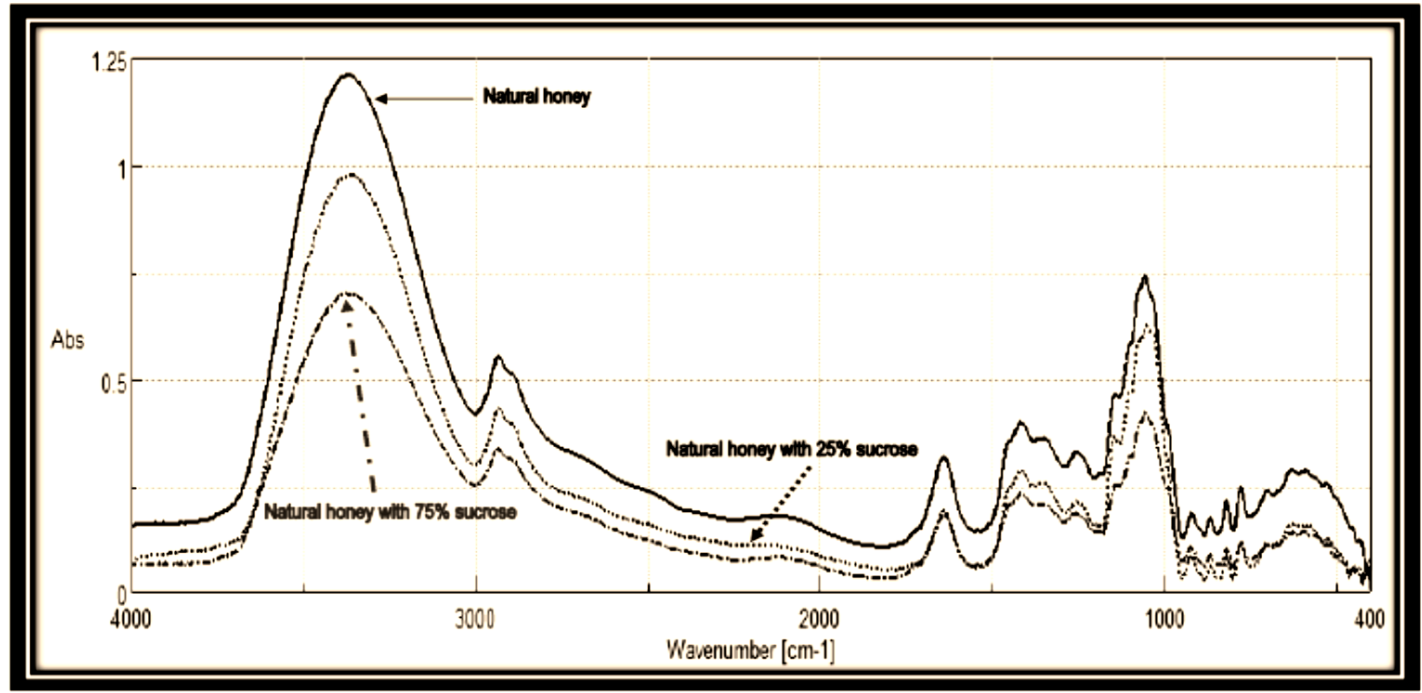

Fig. 9. FT-IR spectral bands of authentic and adulterated honey with different sucrose concentration levels

The bands in the $\left(3363: 2886 \mathrm{~cm}^{-1}\right)$ region are assigned to Stretching $\mathrm{OH}, \mathrm{C}-\mathrm{H}$ stretching symmetric of carboxylic acid and $\mathrm{NH} 3$ band of free amino acids and $\mathrm{C}-\mathrm{H}$ stretching asymmetric of alkene, while those around (1640:1230 $\mathrm{cm}^{-1}$ ) are due to lower water content in the samples and they are characteristic to $\mathrm{O}-\mathrm{H}$ Bending, $\mathrm{O}-\mathrm{CH}$ Bending, $\mathrm{OH}$ Bending of $\mathrm{C}-\mathrm{OH}$ group, $\mathrm{C}-\mathrm{C}-\mathrm{H}$ bending, $\mathrm{OH}$ bending of $\mathrm{C}-\mathrm{OH}$ group and $\mathrm{C}-\mathrm{C}-\mathrm{H}$ bending which indicates that discrimination of honey sugars is based mostly on the differences in these critical regions related to sugars in the spectra (Sivakesava and Irudayaraj, 2001). The last region from $921: 1189 \mathrm{~cm}^{-1}$ is mainly corresponds to $\mathrm{C}-\mathrm{OH}$ bending, $\mathrm{C}-\mathrm{C}$ stretching, $\mathrm{C}-\mathrm{O}$ stretching of $\mathrm{C}-\mathrm{O}-\mathrm{C}$, combination of $\mathrm{C}-\mathrm{O}$ and $\mathrm{C}-\mathrm{C}$ stretching, $\mathrm{CH} 2$ out of plane deformation and $\mathrm{C}-\mathrm{H}$ bending of carbohydrates.

Adulterated honey samples with glucose were characterized with specific spectral peaks where the absorbance was increased by increasing the ratio of adulteration with glucose at 1087, 1105, 1189 and $984 \mathrm{~cm}^{-1}$ while the adulteration with sucrose led to increase in the absorbance of spectral bands which are characterized for sucrose at 1054, 1149 and $984 \mathrm{~cm}^{-1}$ especially in adulterated authentic honey with sucrose (50:50\%).

Fig. (10) shows FT-IR spectral bands of adulterated honey (product like honey) with sucrose $100 \%$, glucose $100 \%$ and mixture of sucrose $(50 \%)$ plus glucose $(50 \%)$. Adulterated sucrose honey $(100 \%)$ has a definite spectral peaks that attributed to main functional groups in sucrose with a high absorbance at 922, 988, 1051, and 1138 $\mathrm{cm}^{-1}$, while honey with $100 \%$ glucose was characterized with spectral bands at 993, 1049, 1078, 1106 and $1152 \mathrm{~cm}^{-1}$ with high absorbance. In mixed adulterated honey with $50 \%$ sucrose plus $50 \%$ glucose, it was found that some of characteristic bands were high in their absorbance than sucrose and low in their absorbance than glucose such as 921, 989, 1048, 1078 and $1151 \mathrm{~cm}^{-1}$. 


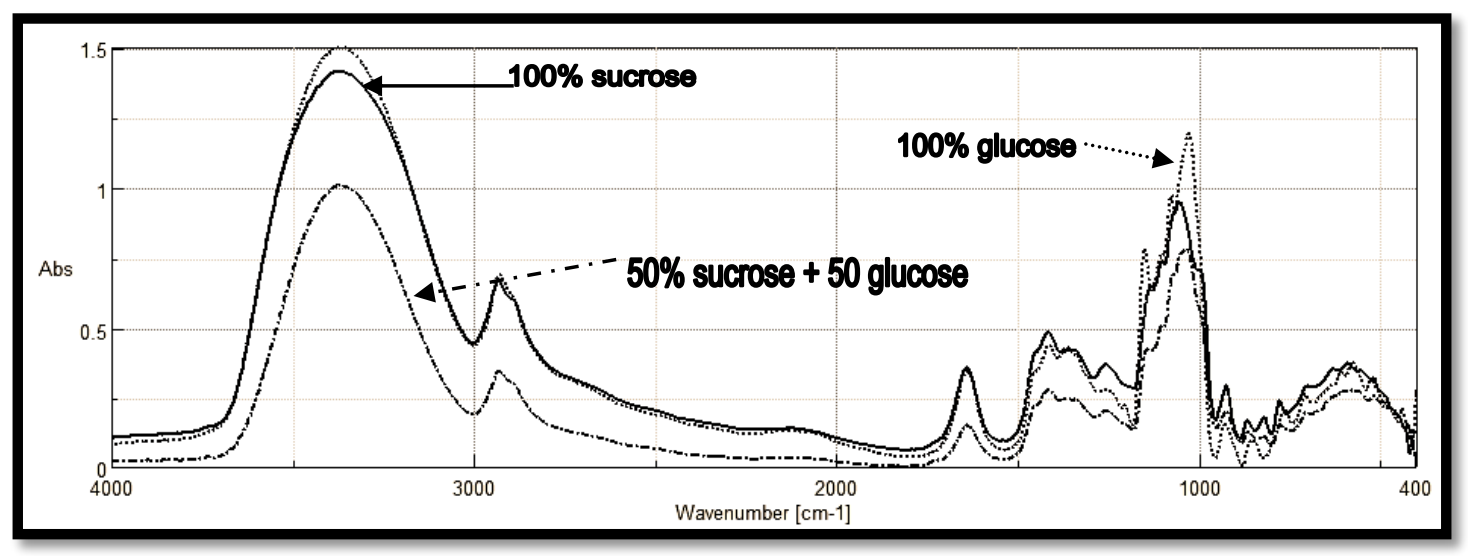

Fig. 10. FT-IR spectral bands of full adulterated honey of $100 \%$ sucrose, $100 \%$ glucose or $50 \%$ sucrose plus $50 \%$ glucose syrup

\section{ACKNOWLEDGMENT}

The present research is financed by the Science and Technology Development Fund (STDF), Egypt, Grant No 1062.

\section{REFERANCES}

Anjos, O., Campos, M.G., Ruiz, C.P. and Antunes, P. 2015. Application of FTIR-ATR spectroscopy to the quantification of sugar in honey. Food Chem., 169: 218-223.

AOAC, 1990. Official Methods of Analysis, $15^{\text {th }}$ Ed., Arlington: Association of Official Analytical Chemists, Inc

Arvanitoyannis, I.S., Halhoub, C.C., Gotsiou, P., Lydakis-Simantiris, $N$. and Kefalas, $P$. 2005. Novel quality control methods in conjunction with chemometrics (multivariate analysis) for detecting honey authenticity. Crit. Rev. of Food Sci. and Nutr., 45:193-203.

Cienfuegos, E., Casar, I. and Morales, P. 1997. Carbon isotopic composition of Mexican honey. J. Apicultural Res., 36: 169-179.

Codex Alimentarius Commetee on Sugars 2001. Codex standard 12, Revised Codex Standard for Honey. Stand. Methods 11: 1-7.

Cotte, J.F., Casabianca, H., Chardon, S., Heritier, J.L. and Grenier-Loustalot, M.F. 2003. Application of carbohydrate analysis to verify honey authenticity. J. Chromatography A, 1021: 145-155.

Edelmann, A., Diewock, J., Schuster, K.C. and Lendl, B. 2001. Rapid method for the discrimination of red wine cultivars based on mid- infrared spectroscopy of phenolic wine extracts. J. Agric. Food Chem., 49: 1139-1145.

European Commission 2002. Council Directive 2001/110/EC of 20 December 2001 relating to honey. Off. J. Europ. Communities, L10: 4752.

Gonzalez, M.I., Marquez, M.E., Sanchez, S.I. and Gonzalez, R.B. 1998. Detection of honey adulteration with beet sugar using stable isotope methodology. Food Chem., 61: 281-286.

Hewitson J. 2009. Composition of honey, http://www-saps. plantsci.cam.ac.uk/records/rec336.htm

Manzanares, A.B., García, Z.H., Galdón, B.R., Rodríguez, E.R. and Romero, C.D. 2011. Differentiation of blossom and honeydew honeys using multivariate analysis on the physicochemical parameters and sugar composition. Food Chem., 126: 664-672.

Manzanares, A.B., García, Z.H., Galdón, B.R., Rodríguez, E.R. and Romero, C.D. 2014. Physicochemical characteristics of minor monofloral honeys from Tenerife, Spain. Food Sci. Technol., 55: 572-578.

Mateo, R. and Bosch-Reig, F. 1998. Classification of Spanish unifloral honeys by discriminant analysis of electrical conductivity, color, water content, sugars and $\mathrm{pH}$. J. Agric. Food Chem., 46: 393-400.

McClave, J.T. and Benson, P.G. 1991. Statistics for Business and Economics. Max Well Macmillian International Editions. Dellen Publishing Co. USA., pp. 272-295.

Oddo, P.L. and Piro, R. 2004. Main European unifloreal honeys: descriptive sheets. Apidologie, 35: 8-81. 
Oddo, P.L., Piazz, M.G., Sabatini, A.G. and Aocorti, M. 1995. Characterisation of unifloral honeys. Apidologie, 26: 453-465.
Ozaki, Y. 1999. Raman spectroscopy. In M.M. Mossoba (Ed.), Spectral methods in food analysis instrumentation and applications. Marcel Dekker, New York, USA, pp.427-462.

Özyurt, G. 2013. Effects of rosemary (rosmarinus officinalis) extract addition on oxidative stability of fried sea bream (sparus aurata) during chill storage $\left(4^{\circ} \mathrm{C}\right)$. J. Food Process. Preserv. 37: 1039-1042.

Paulus, K., Zacharias, R., Robinson, L. and Geidel, H. 1979. Kritischebetrachtungen Zur "Bewertenden Prüfung Mit Skale Als Einemwesentlichen Verfahren Der Sensorischen Analyse. Lebensmittel-Wissenschaft und Technologie, 12 (1): 52-61. (C. F. Özyurt, 2013).

Paradkar, M.M. and Irudayaraj, J. 2001. Discrimination and classification of beet and cane inverts in honey by FT-Raman spectroscopy. Food Chem. 76(2): 231-239.

Sancho, M.T., Muniategui, S., Huidobro, J.F. and Simal, J. 1991. Correlation between the electrical conductivity of honey in humid and dry matter, Apidologie, 22: 221-227.

Sivakesava, S. and Irudayaraj, J. 2001. Prediction of inverted cane sugar adulteration of honey by Fourier transform infrared spectroscopy. J Food Sci., 66: 972-978.

Velázquez T.G., Loa, G.M.Z. and Espinoza, Y. 2009. Application of FTIR-HATR spectroscopy and multivariate analysis to the quantification of adulterants in Mexican honeys. Food Res. Inter., 42(3): 313-318. 